Vol. 41, No. 5

(pp 267-274)

\title{
In-hospital Phase of Postoperative Cardiac Rehabilitation in Elderly Patients with Aortic Stenosis
}

\author{
Masakazu SAITOH, PT, Yohei SHIOTANI, PT, Shogo NAKASHIMA, PT, Reina UEWAKI, PT, \\ Kentaro HORI, PT, Tetsuya OZAWA, PT, Kana KAWAI, PT, Yuichi ADACHI, PT, \\ Yuko IWASA, PT, Aika KOZONO, PT \\ Department of Physiotherapy, Sakakibara Heart Institute \\ Nobuo MOROTOMI, MD \\ Department of cardiac rehabilitation, Sakakibara Heart Institute \\ Masatoshi NAGAYAMA, MD, Morimasa TAKAYAMA, MD \\ Department of Cardiology, Sakakibara Heart Institute
}

Purpose: The aim of this study was to evaluate the progress of postoperative cardiac rehabilitation and physical function in elderly patients after transcatheter aortic valve replacement (TAVR).

Methods: One hundred thirty-nine patients aged over 65 years with severe aortic stenosis (54 males and 85 females, aged $77 \pm 7$ years) who underwent elective conventional open heart AVR or TAVR were selected and divided into 3 groups; group A (AVR, < 80 years), group B (AVR $\geq 80$ years), group C (TAVR). We evaluated the progress of postoperative cardiac rehabilitation and physical function at discharge. We assessed the ability of 100-m unassisted walk as a progress criterion of cardiac rehabilitation, and the short physical performance battery (SPPB) as an indicator of physical function before cardiac surgery and at discharge.

Results: Preoperative and postoperative SPPB score in group C were significantly lower than that in groups A and B ( $\mathrm{p}<0.05)$. Additionally, achievement of $100-\mathrm{m}$ unassisted walk was significantly delayed in group $\mathrm{C}$ compared with groups $\mathrm{A}$ and $\mathrm{B}$, although postoperative hospital stay was not significantly different among 3 groups.

Conclusion: Physical function of patients who underwent TAVR was considerably lower than elderly patients who had conventional open heart AVR. Similarly, progress of postoperative cardiac rehabilitation was delayed in patients who underwent TAVR compared with those who underwent conventional open heart AVR. 